Original Article

\title{
DEVELOPMENT AND VALIDATION OF CARBAMAZEPINE PLASMA CONCENTRATIONS MEASUREMENT AND ITS APPLICATION ON EPILEPSY PATIENTS
}

\author{
ASTRI BUDIKAYANTI ${ }^{a, b}$, CHISWYTA CHALIANA', MELVA LOUISA ${ }^{c}$, RIANTO SETIABUDYc
}

aPhD Candidate in Biomedical Sciences, Faculty of Medicine, Universitas Indonesia, bepartment of Neurology, Faculty of Medicine, Universitas Indonesia/Cipto Mangunkusumo General Hospital, Jakarta, Indonesia, 'Department of Clinical Pharmacology, Faculty of Medicine, Universitas Indonesia

Email: astri_br@yahoo.com

Received: 25 Apr 2017 Revised and Accepted: 13 Jul 2017

\section{ABSTRACT}

Objective: To develop and validate high-performance liquid chromatography with photodiode array (HPLC-PDA) detector as a method for measuring carbamazepine plasma concentrations in epilepsy patients treated with monotherapy or polytherapy.

Methods: Carbamazepine was extracted from epilepsy patients' plasma through liquid-liquid extraction, using protein precipitation with chloroform. Analysis was performed using HPLC with Inertsil DS-4 C18 $(4.6 \times 150 \mathrm{~mm}), 5 \mu \mathrm{m}$ particle size column. The optimal condition for separation was established in a mobile phase consisting of acetonitrile: water (50:50) at a flow rate of $1.0 \mathrm{ml} / \mathrm{min}$, detected by PDA detector at 220 $\mathrm{nm}$. Propylparaben was used as the internal standard. The retention time was $3.5 \mathrm{~min}$.

Results: Linearity was obtained over a concentration range of $0.5-16 \mu \mathrm{g} / \mathrm{ml}$ with $\mathrm{r}=0.999$. The method showed good intra-and inter-day precision and accuracy of more than $90 \%$ difference (\% diff) and $95 \%$ relative standard deviation (RSD). Lower limit of quantification (LOQ) was $0.5 \mu \mathrm{g} / \mathrm{ml}$ and lower limit of detection (LOD) was $0.2 \mu \mathrm{g} / \mathrm{ml}$ with $100 \%$ accuracy and more than $90 \%$ precision. Recovery test was nearly $100 \%$. Stability of carbamazepine plasma concentration in 3 epilepsy patients was measured on the first and third month of treatment, ranging between 83.5 to $98.7 \%$. When used to compare carbamazepine as a monotherapy versus polytherapy, the method showed good selectivity.

Conclusion: The present HPLC method was valid for measuring carbamazepine plasma concentrations in epilepsy patients treated with monotherapy or polytherapy. This method meets the standard in the EMEA guideline in terms of linearity, precision, and accuracy, also selectivity in epilepsy patients treated with polytherapy.

Keywords: Carbamazepine plasma concentration, HPLC, Validation, Epilepsy patients, Monotherapy or polytherapy

(C) 2017 The Authors. Published by Innovare Academic Sciences Pvt Ltd. This is an open access article under the CC BY license (http://creativecommons.org/licenses/by/4.0/) DOI: http://dx.doi.org/10.22159/ijpps.2017v9i9.19402

\section{INTRODUCTION}

Carbamazepine is a hydrophobic, weakly acidic, non-polar aromatic ester, highly soluble in alcohol (fig. 1). It is a first-generation anti epileptic drug (AED), used as a first-line therapy for focal epilepsy. However, $30 \%$ of patients with focal epilepsy do not respond to maximum dosages of carbamazepine, resulting in the need to administer polytherapy with additional AEDs to control seizures, which may lead to drug interactions. Measurements of specific drug concentrations in the plasma of patients on polytherapy may not be reliable due to the selectivity of multidrug measurements.

There are various methods to measure levels of carbamazepine in plasma. One of the simplest and most accurate methods is highperformance liquid chromatography (HPLC) [1]. Previous studies indicated that HPLC was adequate, effective, suitable, simple, rapid, highly sensitive, also had a good intra-day and inter-day precision and an accuracy of $>90 \%$ [1-6]. Considering many patients also use other AEDs, the physician has to make sure that the measurement of carbamazepine plasma levels is unaffected by the presence of other AED. Only few publications on methods of plasma concentration measurements described the implementation of measurements in patients, especially in polytherapy. The rationale of this study was to develop and validate a simple, accurate, rapid, precise, reproducible HPLC method with photodiode array (PDA) detection for quantification of carbamazepine plasma concentration. In this study, we developed a method to measure carbamazepine plasma concentration in epilepsy patients treated with carbamazepine as a monotherapy or polytherapy.

\section{MATERIALS AND METHODS}

\section{Instruments}

We used a HPLC system with separation module by Waters 2695,
Waters 2998 PDA Detector (Waters, USA), Inertsil column ODS-4 C18 ( $4.6 \times 150 \mathrm{~mm}$ ), $5 \mu \mathrm{m}$ pore size (GL Sciences, Japan), a vacuum filter, and Whatman cellulose nitrate and $0.45 \mu \mathrm{m}$ nylon membrane filter.<smiles>NC(=O)N1c2ccccc2C=Cc2ccccc21</smiles>

Fig. 1: Chemical structure of carbamazepine [1]

\section{Chemical solutions and reagents}

Carbamazepine (cat no.94496, Fluka), propylparaben, acetonitrile, methanol, aquabidest, and hydrochloric acid were purchased from E-Merck. Clobazam, phenytoin, phenobarbital, clonazepam, and folic acid are generic drugs produced by Indonesian drug manufacturers. Other drugs used include Depakote ${ }^{\mathrm{TM}}$ containing valproic acid (Abbott), Lamictal ${ }^{\mathrm{TM}}$ containing lamotrigine and Keppra ${ }^{\mathrm{TM}}$ containing levetiracetam (Glaxo Smith Kline), and Topamax ${ }^{\mathrm{TM}}$ containing topiramate (Soho).

\section{Preparation of standard solutions}

Five mg of carbamazepine and propylparaben were weighed, separately put in a $0.5 \mathrm{ml}$ measuring flask, then diluted with methanol until the desired concentrations were reached. The concentration of each standard solution was $1 \mathrm{mg} / \mathrm{ml}$ and each solution was stored at $4{ }^{\circ} \mathrm{C}$.

Optimum wavelength analysis

Carbamazepine standard solution was diluted in methanol to make a 
solution with a concentration of $10.0 \mu \mathrm{g} / \mathrm{ml}$. Wavelength curve of the carbamazepine standard solution was measured with PDA to obtain optimum wavelength analysis.

\section{Sample preparation}

\section{Mobile phase composition}

Water, acetonitrile and methanol were filtered with a vacuum pump and Whatman $0.45 \mu \mathrm{m}$ filter and then degassed for 5 min. A $30 \mu \mathrm{l}$ solution consisting of $1 \mathrm{mg} / \mathrm{ml}$ carbamazepine and propylparaben was injected to the HPLC instrument with a mobile phase containing water: acetonitrile in a 50:50 ratio. The flow rate was $1 \mathrm{ml} / \mathrm{min}$.

\section{Carbamazepine plasma sample preparation}

Working solution consisted of $250 \mu \mathrm{l}$ blank plasma, $50 \mu \mathrm{l}$ carbamazepine standard in different concentrations, $50 \mu \mathrm{l}$ propylparaben $(100 \mu \mathrm{g} / \mathrm{ml})$ and $50 \mu \mathrm{l} \mathrm{HCl} \mathrm{10 \%} \mathrm{was} \mathrm{added} \mathrm{with} 3 \mathrm{ml}$ of chloroform after a 15-s vortex. After another 1-min vortex, the working solution was centrifuged in $4000 \mathrm{ppm}$ for $10 \mathrm{~min}$. Then the supernatant was removed to glass tubes to be evaporated with nitrogen in $40{ }^{\circ} \mathrm{C}$ for $20 \mathrm{~min}$. Dry extract was reconstituted with mobile phase solution and $30 \mu \mathrm{l}$ of this solution was injected to the HPLC.

\section{Methods of validation}

The validation method was done according to The 2011 Guideline on
Bioanalytical Method Validation by the European Medicines Agency. Typical validation characteristics to be considered according to the guidelines include calibration curve, the lower limit of quantification, within-and between-run accuracy and precision, carry-over, dilution integrity, selectivity and stability [7].

\section{Application for epilepsy patients}

This study was part of a clinical research approved by the Ethics Committee of Faculty of Medicine Universitas Indonesia with ethical approval number 895UN2. F1/ETIK/2014. A number of epilepsy patients undergoing monotherapy or polytherapy were included in this study as a part of method development and validation.

\section{RESULTS}

\section{The HPLC method}

Despite the many options available to measure carbamazepine plasma levels, HPLC was considered the most appropriate. Separation was performed using a $150 \mathrm{~mm}$ column. Optimum wavelength for analysis detected by PDA was $\lambda=220 \mathrm{~nm}$. The composition of 50:50 water: acetonitrile was chosen as the mobile phase. Retention time was $3.5 \mathrm{~min}$ at a flow rate of $1 \mathrm{ml} / \mathrm{min}$ for a 30 $\mu \mathrm{l}$-injected volume. Total run time for each assay was approximately 8 min (fig. 2).
A

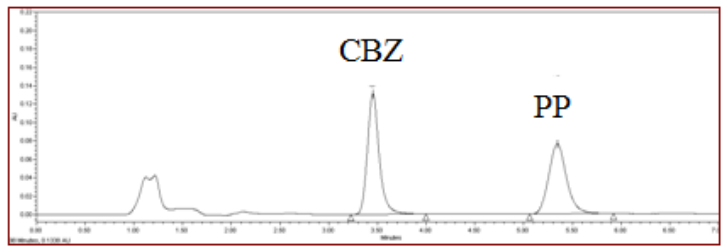

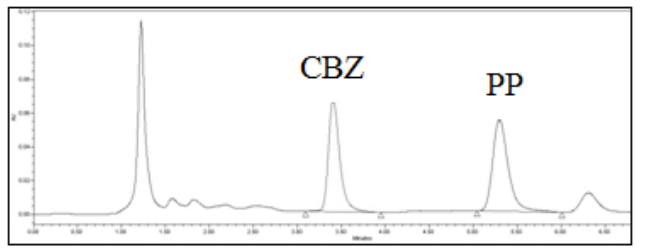

Fig. 2: Chromatogram of carbamazepine (CBZ) and propylparaben (PP) as internal standard; (A): non-extraction carbamazepine; (B): extraction carbamazepine

\section{Range, linearity and calibration curve}

The desired range was selected based on the need to detect a specific range of carbamazepine concentration for clinical use. The therapeutic range used in clinical practice based on an international epilepsy guideline is $4-12 \mu \mathrm{g} / \mathrm{ml}[8]$. To date, there is no available data about therapeutic concentration range of carbamazepine in Indonesian subjects. Based on clinical experience, some patients may respond to doses lower than the recommended posology. In contrast, some patients may show a partial response to a certain therapeutic dose, but failed to achieve complete response despite being given a higher dose; thus the range of 0.5 to $16.00 \mu \mathrm{g} / \mathrm{ml}$ was decided for this study.
A minimum of 5 concentrations was recommended by the international conference of harmonisation (ICH) guideline to establish linearity [9]. In this study, linearity was evaluated across the range of $0.5,1.0,2.0,4.0,8.0,16.0 \mu \mathrm{g} / \mathrm{ml}$ and low, medium and high concentration at $1.5,3.0$ and $12.0 \mu \mathrm{g} / \mathrm{ml}$, respectively, along with a blank sample without internal standard, and a zero sample with internal standard.

Extraction was done following the sample preparation procedure. Plot signal of peak area $(y)$ produced by the HPLC method at each concentration $(\mathrm{x})$ was calculated using linear regression. The correlation coefficient of calibration curve was $\mathrm{y}=0.2254 \mathrm{x}+0.0321$ ( $r=0.999)$ (fig. 3).

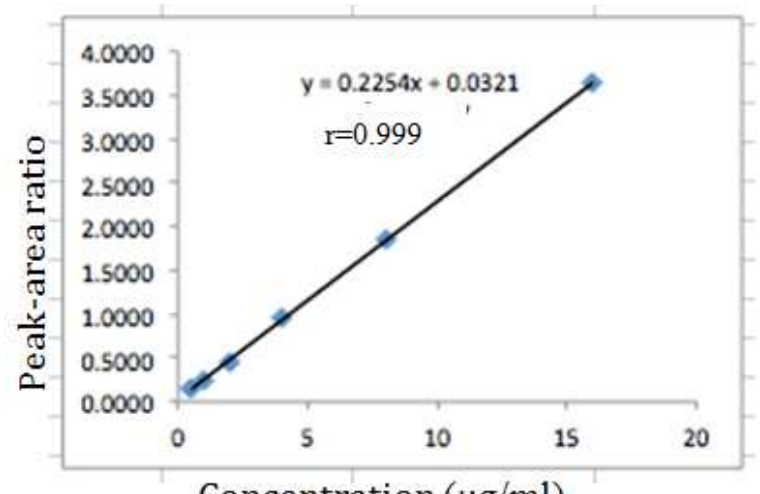

Concentration $(\mathrm{ug} / \mathrm{ml})$

Fig. 3: Carbamazepine calibration curve of concentration versus peak-area ratio 


\section{Lower limit of quantification (LOQ) and detection (LOD)}

Lower limit of quantification (LOQ) was determined at $0.5 \mu \mathrm{g} / \mathrm{ml}$, the minimum level at which carbamazepine can be reliably detected. Lower limit of detection (LOD) was determined at $0.2 \mu \mathrm{g} / \mathrm{ml}$. The accuracy of LOQ was $100.31 \%$ and precision was $92.5 \%$. Accuracy of LOD was $101.94 \%$ and precision was $96.56 \%$.

\section{Precision}

The ICH recommends assessing precision using a minimum of 9 assessments covering specific ranges, for instance, assessing 3 different concentrations, each with 3 replicates, for repeatability. Intermediate precision was expressed in different days. Assessment of intra-day precision in this study was done on 5 replicates of samples with low, medium, and high concentration.

The intra-day precision was more than $90 \%$ difference (\% diff) and $95 \%$ relative standard deviation (RSD). Inter-day precision was assessed using 6 replicates in $9 \mathrm{~d}$, also resulting in more than $90 \%$ diff and 95\% RSD (table 1).

Table 1: Precision intra-and inter-day of carbamazepine plasma

\begin{tabular}{|c|c|c|c|c|}
\hline \multirow[t]{2}{*}{ Concentration $(\mu \mathrm{g} / \mathrm{ml})$} & \multicolumn{2}{|c|}{ Intra-day precision } & \multicolumn{2}{|c|}{ Inter-day precision } \\
\hline & $\%$ diff & RSD $^{\text {a }}(\%)$ & $\%$ diff & $\%$ RSDa $^{a}$ \\
\hline 1.5 & 98.1 & 3.40 & 95.9 & 3.39 \\
\hline 3 & 103.6 & 3.57 & 97.5 & 4.38 \\
\hline 12 & 104.6 & 4.13 & 105.6 & 3.66 \\
\hline
\end{tabular}

${ }^{\mathrm{a}} \mathrm{RSD}=$ relative standard deviation

\section{Accuracy}

Accuracy was determined using a minimum of 9 assessments for precision. Accuracy is reported as percent recovery. The US food and drugs administration (FDA) criteria suggested a mean percent recovery of $100 \pm 2 \%$ at each concentration and within $80-120 \%$ of target concentration [8]. In this study, the mean of recovery at 1.5, 3 and $12 \mu \mathrm{g} / \mathrm{ml}$ was $97 \%, 91 \%$, and $94 \%$, respectively (table 2).

Table 2: Accuracy and mean of recovery

\begin{tabular}{lll}
\hline Concentration $(\boldsymbol{\mu g} / \mathbf{m l})$ & Recovery $(\%)$ & \\
\cline { 2 - 3 } & \% diff & \% RSD $^{\mathbf{a}}$ \\
\hline 1.5 & 97 & 10.88 \\
3 & 91 & 8.11 \\
12 & 94 & 3.92 \\
\hline
\end{tabular}

aRSD = relative standard deviation

\section{Carry-over}

Carry-over was assessed through a 5-time consecutive injection of blank samples followed by highly concentrated calibration standard. The carry-over was less than $20 \%$ of the lower limit of quantification and $5 \%$ for the internal standard.

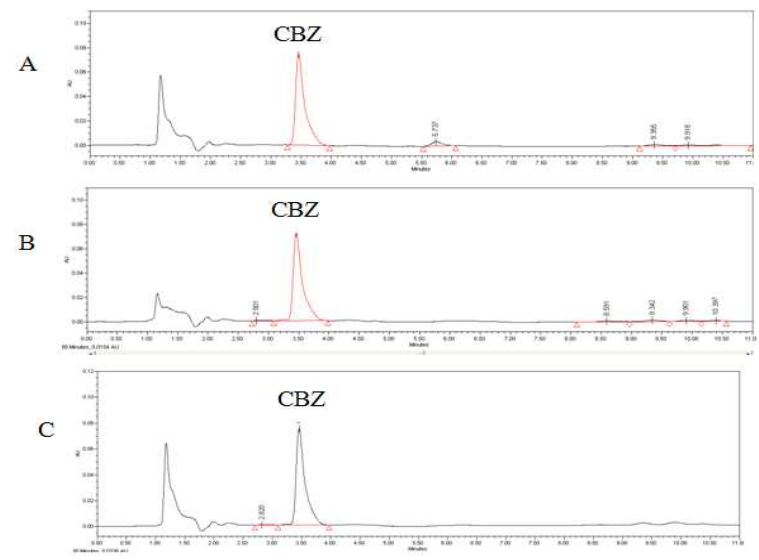

Fig. 4: Selectivity; (A): Carbamazepine and clobazam; (B): Carbamazepine and folic acid; (C): Carbamazepine and valproic acid

\section{Dilution integrity}

Dilution integrity was demonstrated by spiking the matrix with an analyte with a concentration above the LOQ, then the sample was diluted with the blank matrix [7]. Every dilution factor had 5 determinants. The accuracy and precision of the dilutions were within the $15 \%$ range.

\section{Selectivity}

Identification of carbamazepine was determined by evaluating the presence of peak area as a positive result, and no-presence as negative. Impurities were evaluated by adding pure substances of other antiepileptic drugs such as clobazam $10 \mathrm{ppm}$, phenytoin 10 ppm, phenobarbital $10 \mathrm{ppm}$, clonazepam $10 \mathrm{ppm}$, folic acid $10 \mathrm{ppm}$, valproic acid $10 \mathrm{ppm}$, lamotrigine $10 \mathrm{ppm}$, levetiracetam $10 \mathrm{ppm}$, and topiramate $10 \mathrm{ppm}$. Peak area of carbamazepine was unaffected by the presence of other antiepileptic drugs (fig. 4).

\section{Stability}

Stability was determined at the first and third month of the study. The sample was stored at $-20{ }^{\circ} \mathrm{C}$ for $90 \mathrm{~d}$. Across all sample concentrations, \% diff was above $80 \%$ except for $0.5 \mu \mathrm{g} / \mathrm{ml}$ at the first month showed $21 \%$ diff. Carbamazepine plasma concentrations of three drug-resistant epilepsy patients were also determined at the first and third month. All samples showed acceptable standard deviation and RSD (table 3).

Table 3: Stability of carbamazepine plasma concentration of drug-resistant epilepsy patients

\begin{tabular}{llll}
\hline Sample & Concentration $(\boldsymbol{\mu g} / \mathbf{m l})$ & & \% diff \\
\cline { 2 - 4 } & First month & Third month & \\
\hline 1 & 9.24 & 10.88 & 98.8 \\
2 & 6.73 & 6.64 & 11.53 \\
3 & 15.50 & 12.94 & 0.95 \\
\hline
\end{tabular}

${ }^{\mathrm{a} S S D}=$ relative standard deviation 


\section{Application in epilepsy patients}

Ten patients undergoing monotherapy or polytherapy with two or three drugs were selected (table 4). Carbamazepine plasma concentrations were unaffected by the presence of other drugs (fig. 5) and showed consistent results in each dosage and measurement.

Table 4: Carbamazepine plasma concentration in epilepsy patients

\begin{tabular}{llll}
\hline No & Carbamazepine dosages & Other drugs & Carbamazepine plasma concentrations \\
\hline 1. & $400 \mathrm{mg}$ & None & $7.62 \mu \mathrm{g} / \mathrm{ml}$ \\
2. & $400 \mathrm{mg}$ & Folic acid & $6,41 \mu \mathrm{g} / \mathrm{ml}$ \\
3. & $400 \mathrm{mg}$ & Levetiracetam & $9.35 \mu \mathrm{g} / \mathrm{ml}$ \\
4. & $400 \mathrm{mg}$ & Clonazepam & $9.5 \mu \mathrm{g} / \mathrm{ml}$ \\
5. & $400 \mathrm{mg}$ & Lamotrigin & $13.19 \mu \mathrm{g} / \mathrm{ml}$ \\
6. & $600 \mathrm{mg}$ & Valproic acid & $7.95 \mu \mathrm{g} / \mathrm{ml}$ \\
7. & $600 \mathrm{mg}$ & Phenytoin & $8.62 \mu \mathrm{g} / \mathrm{ml}$ \\
8. & $800 \mathrm{mg}$ & Clobazam & $10.08 \mu \mathrm{g} / \mathrm{ml}$ \\
9. & $1100 \mathrm{mg}$ & Valproic acid and phenobarbital & $9.46 \mu \mathrm{g} / \mathrm{ml}$ \\
10. & $1500 \mathrm{mg}$ & Topiramat and clobazam & $14.23 \mu \mathrm{gg} / \mathrm{ml}$ \\
\hline
\end{tabular}

A

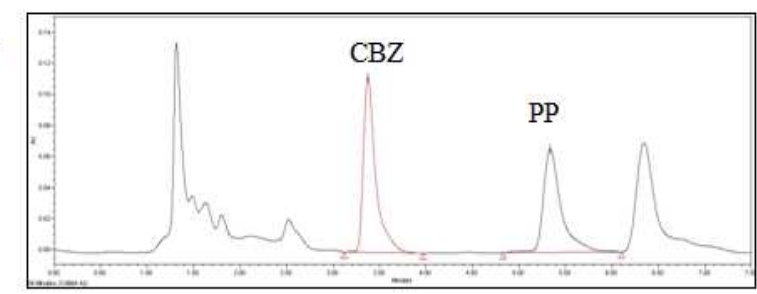

B
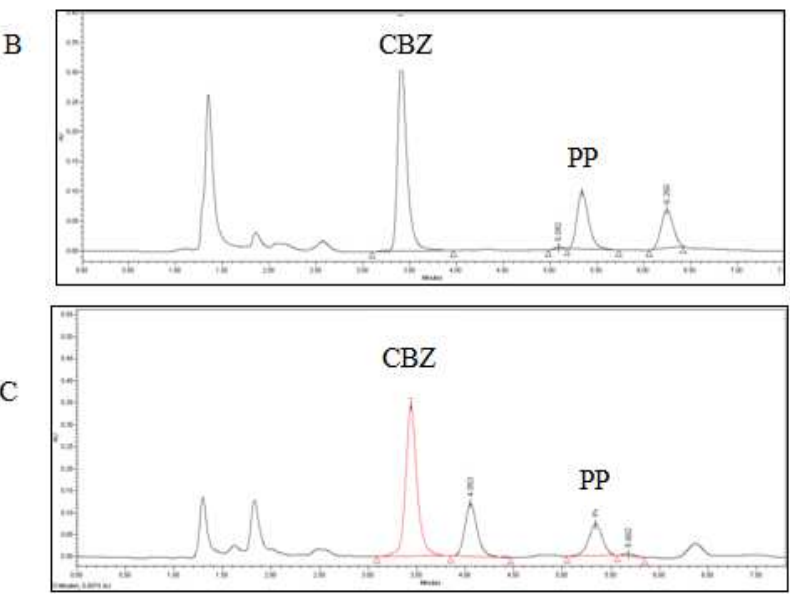

Fig. 5: Chromatogram of carbamazepine (CBZ) and propylparaben $(\mathrm{PP})$ as internal standard, in epilepsy patients; (A): monotherapy; (B): polytherapy with clobazam; (C): Polytherapy with valproic acid and Phenobarbital

\section{DISCUSSION}

Therapeutic drug monitoring (TDM) is important in treating patients with chronic diseases. In epilepsy, patients are treated for at least $3 \mathrm{y}$ after being seizure-free. In many cases, polytherapy is needed to control seizure. The safest way to determine whether a patient needs polytherapy is to first evaluate the plasma levels of the initial medication. If the plasma concentration of the initially administered medication is in the therapeutic range but seizures are not yet controlled, polytherapy may be needed. In polytherapy patients, the plasma concentration of the drug of interest should be unaffected by the presence of other drugs. Only a few publications on various methods of plasma concentration measurements described the implementation of measurements in patients, especially in polytherapy. In pharmaceutical laboratory settings, recent studies that quantify one drug reported a simple, rapid, precise and economical spectrophotometric method using HPLC with UV-Visible [10-11]. Another study quantifies more than one drug, used PDA as drug detector [12]. Meanwhile, a study using patient's plasma reported a selective, accurate and precise HPLC method with PDA [13]. In this study, we used PDA detector to prove the selectivity of the method.

The HPLC technique was validated using the Guidelines on Bioanalytical Method Validation by the EMEA, for the purpose of measuring carbamazepine plasma concentrations in epilepsy patients. Carbamazepine is a hydrophobic and nonpolar compound, hence acetonitrile was chosen as a solvent for the mobile phase, in which the ratio of water: acetonitrile was equal. C18 column was chosen to be the stationary phase with small porous particles. On the surface of the column's porous particles, there is a chemicallybonded phase that separates the sample's compounds. Separation of carbamazepine went well and was detected by the PDA detector, after only 3.5 min following the injection. Other study using solidphase extraction method followed by reverse phase HPLC report the same mobile phase in different ratio. Using the same column and PDA detector, carbamazepine was detected 1 min longer than this study [13]. Another study used different mobile phase for carbamazepine detection in morphine addicted patients, reported the appearance of interfering components [14]. In this study, PDA detector that able to identify multiple components by a comparison of the spectrum proved the method was highly selective in quantify carbamazepine of epilepsy patients' plasma. In monotherapy and polytherapy patients, there was no interference on peak area of carbamazepine.

All parameters of validation were tested and showed good results and were in compliance with the international criteria (EMEA). The linearity of the range chosen had a good correlation coefficient of concentration and peak area ratio. Range linearity in this study could measure the concentration of carbamazepine in most of the collected samples. Precision and accuracy of the test is important, including the LOQ and LOD, in order to have a reliable measurement to base clinical judgments on. Selectivity of this method was satisfactory. Compared to another study; anti epileptic drugs used as polytherapy in this study varied in dosage and types [13].

Moreover, carbamazepine in the patients' plasma was adequately stable. In summary, this method is simple, accurate, and satisfactorily reliable for application in epilepsy patients, especially those undergoing polytherapy.

\section{CONCLUSION}

The usage of HPLC for measuring carbamazepine plasma concentrations in epilepsy patients treated with monotherapy or polytherapy was valid. This method meets the EMEA guideline standard in terms of linearity, precision, and accuracy, also selectivity in epilepsy patients treated with polytherapy.

\section{AUTHOR CONTRIBUTION}

Astri Budikayanti as the first author had done almost all of the steps in this study. Chiswyta Chaliana had a contribution in preparation and laboratory procedures. Melva Louisa was the laboratory supervisor, and Rianto Setiabudy was the mentor of the study. 


\section{CONFLICTS OF INTERESTS}

All authors have none to declare

\section{REFERENCES}

1. Datar PA. Quantitative bio analytical and analytical method development of dibenzazepine derivative, carbamazepine: a review. JPA 2015;5:213-22.

2. Ezzeldin E, Shahat AA, Basudan OA. Development and validation of an HPLC method for the determination of carbamazepine in human plasma. Life Sci J 2013;10:2159-63.

3. Queiroz RHC, Bertucci C, Malfara WR, Dreossi SAC, Chaves AR, Valerio DAL, et al. Quantification of carbamazepine, carbamazepine-10,11-epoxide, phenytoin and phenobarbital in plasma samples by stir bar-sorptive extraction and liquid chromatography. J Pharm Biomed Anal 2008;48:428-34.

4. Dzodic P, Zavanovic L, Protic A, Ivanovic I, VelickovicRadovanovic R, Spasic M, et al. Development and validation of a solid phase extraction-HPLC method for the determination of carbamazepine and its metabolites, carbamazepine epoxide and carbamazepine trans-diol, in plasma. J Serb Chem Soc 2012;77:1423-36.

5. Serralheiro A, Alves G, Fortuna A, Rocha M, Falcao A. First HPLC-UV method for rapid and simultaneous quantification of phenobarbital, primidone, phenytoin, carbamazepine, carbamazepine-10,11-epoxide. J Chromatogr B 2013;925:1-9.

6. Demirkaya F, Kadioglu Y. Determination of carbamazepine using RP-HPLC method in pharmaceutical preparations. FABAD J Pharm Sci 2005;30;78-82.

7. European Medicines Agency. Guideline on bio analytical method validation. United Kingdom: European Medicines Agency; 2011.

8. Tolou-Ghamari Z, Zare M, Habibabadi JM, Najafi MZ. A quick review of carbamazepine pharmacokinetics in epilepsy. J Res Med Sci 2013:Suppl 1:S81-5.

9. Center for Drug Evaluation and Research (U. S.), Center for Biologics Evaluation and Research (U. S.), and International
Conference on Harmonisation. Guidance for industry: Q2B validation of analytical procedures, methodology. Maryland: $U$. S. Dept. of Health and Human Services, Food and Drug Administration, Center for Drug Evaluation and Research; 1996.

10. Zadbuke N, Shahi S, Jadhav A, Borde S. Development and validation of a UV-visible spectroscopic method for estimation of carbamazepine in bulk and tablet dosage form. Int J Pharm Pharm Sci 2016;8:234-8.

11. Tonic-Ribarska J, Sterjev Z, Cvetkosvska E, Kuzmanovski I, Kiteva G, Suturkova L, et al. Optimization and validation of a bioanalytical SPE-HPLC method for the simultaneous determination of carbamazepine and its main metabolite, carbamazepine-10, 11-epoxide, in plasma. Macedonian Pharm Bull 2011;57:53-61.

12. Acharya M, AK J, Garud N. Stability indicating reversed phasehigh performance liquid chromatography method development and validation for simultaneous determination of related substances of citicoline and piracetam in pharmaceutical dosage form. Asian J Pharm Clin Res 2016;9:292-7.

13. Yunoos M, Sankar G. A validated stability indicating a highperformance liquid chromatographic method for simultaneous determination of metformin HCL and dapaglifozin in bulk drug and tablet dosage form. Asian J Pharm Clin Res 2015;8:320-6.

14. Ghafghazi S, Zanjani TM, Vosough M, Sabetkasaei M. Interference-free determination of carbamazepine in human serum using high-performance liquid chromatography: a comprehensive research with three-way calibration methods. Int J Pharmacol Res 2017;16:120-31.

\section{How to cite this article}

- Astri Budikayanti, Chiswyta Chaliana, Melva Louisa, Rianto Setiabudy. Development and validation of carbamazepine plasma concentrations measurement and its application on epilepsy patients. Int J Pharm Pharm Sci 2017;9(9):87-91. 